\section{Summary of: Complexities associated with orthodontic services in the National Health Service}

\author{
S. Richmond ${ }^{1}$ and A. Karki ${ }^{2}$
}

\section{FULL PAPER DETAILS}

${ }_{1}$ Cardiff University, Applied Clinical Research and Public Health, Cardiff Dental School, University Dental Hospital, Heath Park, Cardiff CF14 4XY; ${ }^{2}$ Public Health Wales, Dental Public Health, 1st Floor Mamhilad House, Mamhilad Park Estate, Pontypool NP4 OYP ${ }^{*}$ Correspondence to: Professor Stephen Richmond Email: richmonds@cardiff.ac.uk; Tel:02920742451

Online article number E5 Refereed Paper - accepted 28 October 2011 DOI: 10.1038/sj.bdj.2012.98

${ }^{\circ}$ British Dental Journal 2012; 212: E5

\begin{abstract}
Aim To detail orthodontic provision in Wales. Background In 2006 the new orthodontic contract was introduced in the NHS in England and Wales. Since the introduction of the new contract there have been recent reports of inefficiencies in orthodontic provision in Wales in terms of: orthodontic provision reaching those who need it, type of orthodontic activities undertaken, who is providing orthodontic care, the relative cost-efficiency of the orthodontic services, contracting and performance management of the services and robustness of the orthodontic database. Materials and methods 2008/09 orthodontic data on contracted services were analysed. Data from the salaried services was collected through a questionnaire. Normative orthodontic treatment need was estimated from mid-year population estimates. Results In 2008/09, there were considerable inefficiencies in the orthodontic services in Wales with varied level of access by children living in 22 former local health boards, co-terminus with local authorities in Wales. Total spend on orthodontics in Wales was around £12,718,370. It was estimated that 11,539 (30\%) of 12-17-year-olds required orthodontic treatment. In 2008/09, 11,031 children received orthodontic treatment in all NHS services in Wales indicating a potential shortfall of 508 treatments. Out of 135 GDS/PDS orthodontic contracts, 27 provided no active treatment (only assessments) and 62 provided less than 50 treatments annually. Cost per units of orthodontic activity (UOA) ranged from $€ 58$ to $€ 74$. With improved contracts and efficiency, the orthodontic budget seems sufficient to meet the orthodontic need of the population. Conclusions As with any type of NHS provision, it is important that orthodontic services are competitive, highly efficient and provided on the basis of need. Performance management of orthodontic services should focus on the number of successful orthodontic treatments delivered annually. The personal dental services (PDS) orthodontic contract will need to be modified accordingly.
\end{abstract}

\section{EDITOR'S SUMMARY}

There is a tendency amongst dentists to be 'doers' in the sense that we like to see a project, seek the answer and get on with solving the problem. It may or may not be a personality trait of the people attracted to the profession or it may be a feature of all patient care but it can have some unfortunate consequences.

Amongst these is the mistake of assuming that activity of its sake is always beneficial when in fact some consideration of screening, assessment and organisation can point the way to more effective and efficient ways of achieving the same, or better, outcomes. The purpose, one supposes, of systems.

This important investigation in a discrete geographical area and a well defined specialty is a very good example of how analysis of data within a care- fully delineated sample and with clear objectives can work to the benefit of all concerned. Orthodontics is a treatment mode that is inevitably tinged with emotional outcomes since it involves both appearance and (usually) young people. In such circumstances there is a danger that 'systems' can be construed as being impersonal, uncaring or out of touch and however sensitively they have been constructed there will be cases which require more detailed review. However, refining organisation of patient examination and assessment, adjusting incentives for clinicians to treat patients effectively (which is, after all, what good contracts are ultimately designed to do) and then monitoring ongoing outcomes are all laudable aims of such studies based on data collection and analysis.

This example from Wales might also give some indicators for the way in which well delineated communities might in future, given the proposed health reforms in England, assess, measure and adjust their public health services. Local accountability can show definite benefits but comes at a cost of employing skilled and knowledgeable individuals, which is perhaps where the 'doers' come back into their own.

The full paper can be accessed from the $B D J$ website (www.bdj.co.uk), under 'Research' in the table of contents for Volume 212 issue 3.

Stephen Hancocks Editor-in-Chief

DOI: 10.1038/sj.bdj.2012.117 
TO ACCESS THE BDJ WEBSITE TO READ THE FULL PAPER:

- BDA Members should go to www.bda.org.

- Click the 'login' button on the right-hand side and enter your BDA login details.

- Once you have logged in click the 'BDJ' tab to transfer to the BDJ website with full access.

IF YOUR LOGIN DETAILS DO NOT WORK:

- Get a password reminder: go to www.bda.org, click the login button on the right-hand side and then click the forgotten password link.

- Use a recommended browser: we recommend Microsoft Internet Explorer or Mozilla Firefox.

- Ensure that the security settings on your browser are set to recommended levels.

IF YOU HAVE NOT YET SIGNED UP TO USE THE BDA WEBSITE:

- Go to www.bda.org/getstarted for information on how to start using the BDA website.
IN BRIEF

- Cost-efficiency and cost-effectiveness of orthodontic provision could be improved through better procurement, skill mix and contract service management.

- Comprehensive orthodontic data associated with KPIs will enable improved contract management and provision.

- Re-adjustment of high value treatment costs in line with the national average will allow greater numbers of patients to be treated.

\section{COMMENTARY}

This sprawling and courageous review of NHS orthodontic provision in Wales uses a variety of computations to describe the supply and nature of orthodontic care and referral patterns, as well as its contracting, quality assurance and efficiency. The databases for this evaluation are by no means complete, which also has implications for our views about the service.

In short, the authors detected evidence suggesting possible inappropriate referral, variations in the availability of care with over-supply by up to 51\% in some areas and differences in costs between centres of up to $30 \%$.

The issue here is one of the quality of the service provided. Quality is not simply related to the technical competence of treatment. It refers to whether care is relevant to need and to its effectiveness, efficiency, equity, acceptability and accessibility. The paper might have been more focused under such a quality framework.

As professionals we are expected to deliver care of the highest quality, but at the moment particularly, those of us working in the state sector are under an obligation to work as efficiently as possible. Indeed, the health minister of the Welsh government observed that in order to deliver 'sustainable services, the NHS needs to look at how services are delivered locally' in this 'challenging financial environment'.

Reviews of health services always show areas for improvement, and like all good research, this review poses as many questions as it answers. It may be that the data are incomplete or incorrect. However, in order to assure a high quality service the data must be transparent and robust, so it is necessary for both service providers and commissioners to improve data capture. It should also be the case that orthodontists, public health practitioners and commissioners constantly revise the provision of orthodontic services toward greater quality. These data should certainly inform those revisions.

One example of this is the benefit from introducing orthodontic therapists, who might increase efficiency as more patients can be seen at lower unit cost. Who will reap the benefit of this efficiency gain? Orthodontists or the NHS?

\section{P. G. Robinson}

Professor of Dental Public Health, School of Clinical Dentistry,

University of Sheffield

1. Health in Wales. $€ 288$ million extra for NHS in Wales. Gig Cymru NHS Wales, 2011. Online article available at http://www.wales.nhs.uk/ news/20414 (accessed February 2012).

\section{AUTHOR QUESTIONS AND ANSWERS}

1. Why did you undertake this research? There had been reported inefficiencies in orthodontic provision in respect to access to treatment, number of providers, and appropriateness of treatment performed. The provision of the orthodontic services is complex and it was the authors' intention to detail orthodontic activity for each practitioner providing orthodontic care.

2. What would you like to do next in this area to follow on from this work?

As a result of this work there should be an improvement in orthodontic contracting, for example, contracts with practitioners just providing assessment and reviews should be terminated. The focus of orthodontic contracts should be on active treatment and outcome. Once there is uniformity in orthodontic delivery simple algorithms can be devised to highlight the most efficient and effective providers as examples of good practice and reduce or eliminate ineffective activities. 